\title{
The in vitro and in vivo Safety Evaluation of Lactobacillus acidophilus IDCC 3302
}

\author{
Won Yeong Bang ${ }^{1,2 \dagger}$, Seung A Chae ${ }^{2 \dagger}$, O-Hyun Ban ${ }^{1,2}$, Sangki Oh ${ }^{2}$, Chanmi Park ${ }^{2}$, Minjee Lee ${ }^{2}$, Minhye Shin ${ }^{3}$, \\ Jungwoo Yang ${ }^{2 *}$, and Young Hoon Jung ${ }^{1,4 *}$ \\ ${ }^{1}$ School of Food Science and Biotechnology, Kyungpook National University, Daegu 41566, Republic of Korea \\ ${ }^{2}$ Ildong Bioscience, Pyeongtaek 17957, Republic of Korea \\ ${ }^{3}$ Department of Agricultural Biotechnology, Research Institute of Agriculture and Life Science, Seoul National University, Seoul 08826, \\ Republic of Korea \\ ${ }^{4}$ Institute of Fermentation Biotechnology, Kyungpook National University, Daegu 41566, Republic of Korea
}

Received: November 18, 2020 / Revised: December 10, 2020 / Accepted: December 15, 2020

\begin{abstract}
As consumption of healthy foods continues to garner remarkable public attention, ensuring probiotic safety has become a priority. In this study, the safety of Lactobacillus acidophilus IDCC 3302 was assessed in vitro and in vivo. L. acidophilus IDCC 3302 showed negative results for hemolytic and $\beta$-glucuronidase activities. The whole-genome analysis (WGA) revealed that $L$. acidophilus IDCC 3302 did not possess antibiotic resistance or virulence genes. The minimal inhibitory concentrations of $L$. acidophilus IDCC 3302 confirmed its safety concerning antibiotic resistance. Furthermore, L. acidophilus IDCC 3302 was demonstrated to be nontoxic in the oral toxicity test in rats. Therefore, the results suggested that $L$. acidophilus IDCC 3302 might be safe for human consumption.
\end{abstract}

Keywords: Antibiotic resistance, Lactobacillus acidophilus, probiotics, safety evaluation

\section{Introduction}

Probiotics are defined as living microorganisms (i.e., lactic acid bacteria) that benefit human health when ingested appropriately [1, 2]. Lactic acid bacteria (LAB) are found in various habitats, such as humans, plants, and fermented foods [3]. Among the LAB, the Lactobacillus genus has been used as a food additive and starter in the dairy industry [4]. Lactobacillus also produce bacteriocins and exopolysaccharides, which have a protective role in fermented foods and immuneenhancing effects on human health, respectively [5-7].

\footnotetext{
*Corresponding authors

J. Yang

Tel: +82-31-646-3114, Fax: +82-70-7500-2592

E-mail: yjw@ildong.com

Y. H. Jung

Tel: +82-53-950-5777, Fax: +82-53-950-6772

E-mail: younghoonjung@knu.ac.kr

${ }^{\dagger}$ These authors equally contributed to this work.
}

In particular, Lactobacillus acidophilus, which is often found in human intestines, plays a critical role in enhancing the growth of beneficial LABs and maintaining intestinal flora $[8,9]$.

L. acidophilus is "generally recognized as safe" because it is non-pathogenic and has a long history of safe use as a probiotic in various food products such as dairy products and fermented meat $[10,11]$. However, due to rare but adverse events caused by $L$. acidophilus, such as diarrhea and bowel irritation [11, 12], the bacteria's safety has been brought into focus [13, 14]. As a result, the FAO/WHO had introduced a guideline for evaluating probiotics as food in 2002. This guideline includes standardized methods for in vivo and in vitro safety assessment.

The characteristics of the commercially available strain, L. acidophilus IDCC 3302, include 66.3\% autoaggregation, 38.0-93.2\% co-aggregation with pathogens, $51.2 \%$ hydrophobicity, $73.2 \%$ acid tolerance, $59.3 \%$ bile 
tolerances, and antipathogenic effects [15]. In this study, L. acidophilus IDCC 3302's antibiotic resistance and toxigenicity were investigated with whole-genome sequence analysis. L. acidophilus IDCC 3302's phenotypes, such as minimal inhibitory concentration, $\beta$-hemolysis, extracellular enzyme activity, and the production of biological amines and L/D-lactate, were investigated. Finally, an in vivo, acute oral toxicity (AOT) test was performed to access the bacteria's safety. Therefore, this study is valuable to those who plan to determine the safety of probiotics.

\section{Materials and Methods}

\section{Bacterial strain and culture conditions}

L. acidophilus IDCC 3302 (ATCC BAA2845 ${ }^{\mathrm{TM}}$ ), isolated from infant feces, was incubated in MRS (BD Difco, USA) medium at $37^{\circ} \mathrm{C}$ in a static incubator under anaerobic condition. As a positive control for hemolytic activity, Staphylococcus aureus (ATCC 25923) was incubated in brain heart infusion (BHI; BD Difco) medium at $37^{\circ} \mathrm{C}$ and $200 \mathrm{rpm}$.

\section{Whole-genome analysis}

The whole-genome sequencing of $S$. thermophilus IDCC 2201 was performed to identify its virulence and antibiotic resistance gene. The VFDB database was searched for virulence genes [16], and ResFider software (ver. 3.2) with the CARD database were searched for antibiotic resistance genes [17]. The search parameters were set to the identity of $>80 \%$ and coverage of $>80 \%$ for gene identification. Transposases and transferases were annotated using the protein-protein basic local search program (BLASTP) against the NCBI GenBank proteins. Prophage regions were identified using PHASTER web-based program [18].

\section{Antibiotic resistance}

L. acidophilus IDCC 3302 was evaluated for its susceptibility to various antibiotics, which are typically used to treat enterococcal infections. Nine antibiotics, ampicillin, vancomycin, gentamicin, kanamycin, streptomycin, erythromycin, clindamycin, tetracycline, and chloramphenicol were used as recommended by EFSA (2018). The test was performed according to CLSI (Clinical Laboratory Standards Institute) protocol. Briefly, a sin- gle colony from a plate was inoculated in MRS broth and pre-incubated for $16 \mathrm{~h}$. The cultured cells and antibiotic solution were mixed in a 96 -well plate to achieve the initial cell density of $5 \times 10^{5}$ colony-forming unit $(\mathrm{CFU}) / \mathrm{ml}$ and an antibiotic concentration of $0.125-1024 \mu \mathrm{g} / \mathrm{ml}$. Then, the plate was incubated at $37^{\circ} \mathrm{C}$ anaerobically in a static incubator for $18 \mathrm{~h}$. Finally, the optical density of the cells was measured using a microplate reader (BioTek, USA) to determine the lowest antibiotic concentration that completely inhibited cell growth (minimal inhibitory concentrations, or MICs).

\section{$\beta$-Hemolysis activity}

Single colonies of L. acidophilus IDCC 3302 and Staphylococcus aureus ATCC 25923, which acted as the positive control, were incubated for $16 \mathrm{~h}$. The incubated cells were streaked on sheep blood agar plates (BBL Microbiology Systems, USA). The plates were then incubated at $37^{\circ} \mathrm{C}$ for $24 \mathrm{~h}$. Finally, $\beta$-hemolytic activity was indicated by the clear zone that formed around a colony.

\section{Extracellular enzyme activities}

Extracellular enzymatic activities were determined using an API-ZYM kit (BIOMÉRIUX, France). Briefly, a single colony of $L$. acidophilus IDCC 3302 was inoculated and incubated at $37^{\circ} \mathrm{C}$ anaerobically for $16 \mathrm{~h}$. The cells were centrifuged, and cell pellets were adjusted to $1.8 \times 10^{9} \mathrm{CFU} / \mathrm{ml}$ with PBS. The cells were loaded into a 96 -well plate and incubated at $37^{\circ} \mathrm{C}$ for $4 \mathrm{~h}$. Then, one drop of each of ZYM-A and ZYM-B reagents were added to each well. After $5 \mathrm{~min}$, color changes were observed and compared to the manufacturer's standard response chart.

\section{Biogenic amines production}

Biogenic amines (BAs) produced by L. acidophilus IDCC 3302 were analyzed with slight modifications [19]. Five biogenic amines, i.e., tyramine, histamine, putrescine, 2-phenethylamine, and cadaverine, were used as standards as recommended by EFSA [20].

After L. acidophilus IDCC 3302 was cultured in MRS for $16 \mathrm{~h}, 0.5 \mathrm{ml}$ of supernatant from the culture was mixed with $0.5 \mathrm{ml}$ of $0.1 \mathrm{~N} \mathrm{HCl}$. Next, $200 \mu \mathrm{l}$ of saturated $\mathrm{NaHCO}_{3}$ (Sigma-Aldrich, USA), $20 \mu \mathrm{l}$ of $2 \mathrm{M} \mathrm{NaOH}$, and $0.5 \mathrm{ml}$ of $10 \%$ dansyl chloride (10 $\mathrm{mg} / \mathrm{ml}$ acetone) were added to the mixture, followed by derivatization at $70^{\circ} \mathrm{C}$ 
for $10 \mathrm{~min}$. Then, $200 \mu \mathrm{l}$ of $\mathrm{L}$-proline $\left(100 \mathrm{mg} / \mathrm{ml} \mathrm{H}_{2} \mathrm{O}\right)$ was added into derivatized BAs and incubated in a dark room for $15 \mathrm{~min}$ to remove unbound dansyl chloride. Then, acetonitrile (HPLC grade; Sigma-Aldrich) was added to bring the mixture's final volume to $5 \mathrm{ml}$. Finally, the prepared samples were filtered with a $0.45 \mu \mathrm{m}$ membrane filter and analyzed using high-performance liquid chromatography (HPLC; LC-NetII/ ADC, United Kingdom) equipped with an Athena C18 column (4.6 mm $\times 250 \mathrm{~mm}$, ANPEL Laboratory Technologies, China). Acetonitrile solution was used as a mobile phase with a constant flow rate of $0.8 \mathrm{ml} / \mathrm{min}$. The BAs were detected by a UV detector (UV-2075 plus, Jasco), and BAs concentrations were determined according to the calibrated curve.

\section{Determination of L/D-lactate concentrations}

The L-/D-lactate production of $L$. acidophilus IDCC 3302 was determined using the L-/D-lactate enzyme test kit (Megazyme, Ireland). Briefly, $0.1 \mathrm{ml}$ of the supernatant of L. acidophilus IDCC 3302 culture was mixed with $1.5 \mathrm{ml}$ of $\mathrm{H}_{2} \mathrm{O}, 0.5 \mathrm{ml}$ of supplied buffer ( $\mathrm{pH}$ 10.0), $0.1 \mathrm{ml}$ of $\mathrm{NAD}^{+}$solution, and $0.02 \mathrm{ml}$ of glutamatepyruvate transaminase (GPT) and incubated at room temperature for $3 \mathrm{~min}$. Then, the absorbance of D-lactate was measured at $340 \mathrm{~nm}$. Next, $0.02 \mathrm{ml}$ of $2,000 \mathrm{U} / \mathrm{ml}$ lactate dehydrogenase $(\mathrm{LD})$ was added to the above reaction mixture, and the absorbance of D-lactate was measured for 3 min until the $\mathrm{LD}$ reaction stopped. Then, the absorbance of L-lactate was measured at $340 \mathrm{~nm}$. The concentrations of L-/D-lactate were calculated according to the equations according to the manufacturer's instruction.

\section{Acute oral toxicity (AOT) test in rats}

Acute oral toxicity (AOT) test was performed by the Korea Testing \& Research Institute (KTR; Korea) according to the Ministry of Food and Drug Safety and OECD guidelines [21]. Briefly, twelve Crl:CD(SD) female rats aged 9 to 10 weeks were divided into four groups of three rats each. Each group was orally administrated with 300 or $2000 \mathrm{mg}$ of L. acidophilus IDCC 3302 powder in $10 \mathrm{ml}$ sterilized water. The rats' viability, general symptoms, and body weight changes were monitored for 14 days. Finally, 100-ml isoflurane injections were used to euthanize the rats, autopsied, and visually inspect for organ abnormalities.

The animal experiments in this study were conducted by Korea Testing and Research Institute (KTR) under Animal protection act (no. 14651) and laboratory animal act (no. 15278) by Korea government.

\section{Results and Discussion}

\section{Antibiotic resistance and whole-genome analysis}

L. acidophilus IDCC 3302 was susceptible to all of the antibiotics with MIC values at or below the EFSA cutoff values, except for kanamycin (Table 1). The wholegenome analysis revealed that $L$. acidophilus IDCC 3302 did not have any gene similar to antibioticresistant genes (Table S1 and Fig. S1). Thus, the resistance to kanamycin was regarded as an intrinsic trait of this strain. Many Lactobacillus species are relatively tolerant of aminoglycoside antibiotics, i.e., kanamycin [10, 22], likely due to the reduced uptake of aminoglycosides in the absence of cytochrome-mediated transport [23, 24]. For example, $79 \%$ out of 187 isolates from 55 European probiotics products showed kanamycin resistance [25]. Meanwhile, a kanamycin cutoff value was suggested as more than $256 \mathrm{mg} / \mathrm{l}$ for all Lactobacillus species based on MIC values of 37 strains [6]. Additionally, L. acidophilus IDCC 3302 was evaluated for genome sequence similarities to known virulence factors using the VFDB database [16]; it does not carry

Table 1. L. acidophilus IDCC 3302's minimum inhibitory concentrations (MIC) against a variety of antibiotics.

\begin{tabular}{cccccccccc}
\hline & AMP & VAN & GEN & KAN & STR & ERY & CLI & TET & CHL \\
\hline Cutoff value $(\mu \mathrm{g} / \mathrm{ml})$ & 1 & 2 & 16 & 64 & 16 & 1 & 4 & 4 & 4 \\
L. acidophilus IDCC 3302 & $0.5 / \mathrm{S}^{2}$ & $0.5-1 / \mathrm{S}$ & $4-16 / \mathrm{S}$ & $128 / \mathrm{R}^{3}$ & $4 / \mathrm{S}$ & $<0.125 / \mathrm{S}$ & $1-2 / \mathrm{S}$ & $0.25 / \mathrm{S}$ & $2-4 / \mathrm{S}$ \\
\hline
\end{tabular}

${ }^{1}$ EFSA (European Food Safety Authority), 2018. EFSA Journal, 16(3), 5206.

${ }^{2} \mathrm{~S}$ : susceptible, ${ }^{3} \mathrm{R}$ : resistant.

Abbreviations: AMP, ampicillin; CHL, chloramphenicol; CLI, clindamycin; ERY, erythromycin; GEN, gentamicin; KAN, kanamycin; STR, streptomycin; TET, tetracycline; VAN, vancomycin. 
any toxigenic gene. In conclusion, L. acidophilus IDCC 3302 was regarded as safe concerning antibiotic resistance according to genomic evaluation and MIC values tested in this study.

\section{$\boldsymbol{\beta}$-Hemolytic activity}

Hemolysis caused by a bacterial infection, such as invasion, frequently triggers hemolytic symptoms, including anemia, fever, and skin rash [26]. Thus, it is essential to evaluate the hemolytic activity of probiotics to ensure their safety. In this study, L. acidophilus IDCC 3302 produced no clear or greenish zone surrounding the colonies, showing $\gamma$-hemolytic (non-hemolytic) (Fig. S2).

\section{Extracellular enzyme activities}

The extracellular enzymatic profile of $L$. acidophilus IDCC 3302 was investigated using the API ZYM kit (Fig. S3). As probiotics, lactic acid bacteria should not produce $\beta$-glucuronidase, which indicates the formation of potentially carcinogenic compounds, such as cycasin, and toxic steroids, such as estrogen [27]. As expected, $\beta$ -

Table 2. Enzymatic activities of $L$. acidophilus IDCC 3302 using the API-ZYM kit.

\begin{tabular}{|c|c|}
\hline Enzyme & L. acidophilus IDCC 3302 \\
\hline Alkaline phosphate & - \\
\hline Esterase & + \\
\hline Esterase lipase & - \\
\hline Lipase & - \\
\hline Leucine arylamidase & + \\
\hline Valine arylamidase & + \\
\hline Cystine arylamidase & - \\
\hline Trypsin & - \\
\hline a-Chymotrypsin & - \\
\hline Acid phosphatase & + \\
\hline Naphthol-AS-BI-phosphohydrolase & + \\
\hline a-Galactosidase & - \\
\hline$\beta$-Galactosidase & + \\
\hline$\beta$-Glucuronidase & - \\
\hline a-Glucosidase & + \\
\hline$\beta$-Glucosidase & + \\
\hline N-acetyl- $\beta$-glucosaminidase & - \\
\hline a-Mannosidase & - \\
\hline a-Fucosidase & - \\
\hline
\end{tabular}

glucuronidase activity was absent in L. acidophilus IDCC 3302 (Table 2). On the other hand, the presence of $\beta$-glucosidase and $\beta$-galactosidase may be advantageous for human health (Table 2). For example, $\beta$-glucosidase hydrolyzes glucose conjugates from various foods to generate beneficial secondary metabolites in the colon [28]. B-galactosidase, which converts lactose into glucose and galactose, is reported to reduce lactose intolerance [29]. Meanwhile, another strain, such as $L$. acidophilus MVA3, was reported to have neither $\beta$-glucosidase nor 8 galactosidase [30].

\section{Biogenic amines production}

Biogenic amines (BAs) derive from the decarboxylation of amino acids; they can cause toxic effects in humans, such as headache, vomiting, and diarrhea [31]. Typically, lactic acid bacteria are considered the primary producers of BAs in fermented foods. Thus, many studies have been focused on the safety of BA accumulation by lactic acid bacteria [32]. Here, L. acidophilus IDCC 3302 could not produce tyramine, histamine, putrescine, 2-phenethylamine, or cadaverine (data not shown). Among the BAs examined, tyramine and histamine are considered the most important in food safety because they are responsible for scombroid fish poisoning, and food-induced migraine [33]. Some Lactobacillus strains, such as L. sakei, L. plantarum, L. casei, L. paracasei, and $L$. reuteri, were reported to produce tyramine or histamine or both [32]. In conclusion, L. acidophilus IDCC 3302 is determined to be safe concerning biogenic amine production due to its lack of biogenic amine production.

\section{Determination of the ratio of D- to L-lactate}

The bacteria of the Lactobacillus genus can produce lactate from the fermentation of carbohydrates. Lactate exists in two forms, L-lactate, the levorotary enantiomer, and D-lactate, the dextrorotary enantiomer [34, 35]. Because humans do not metabolize D-lactate, its production and accumulation by intestinal microflora might trigger D-lactate acidosis and short bowel syndrome [36]. However, there is no research on the amount of D-lactate produced by intestinal microflora or whether it may trigger symptoms in humans. Although D-lactate concentration of patients with the symptoms is comparatively higher, the risk of D-lactate in healthy 
Table 3. The production of L-/D-lactic acid isomers by $L$. acidophilus IDCC 3302.

\begin{tabular}{ccccc}
\hline Strains & $\begin{array}{c}\text { L-lactic acid } \\
(\mathrm{mg} / \mathrm{ml})\end{array}$ & $\begin{array}{c}\text { D-lactic acid } \\
(\mathrm{mg} / \mathrm{ml})\end{array}$ & \multicolumn{2}{c}{ Ratio of isomers (\%) } \\
\cline { 5 - 6 } & L-form & D-form \\
\hline $\begin{array}{c}\text { L. acidophilus } \\
\text { IDCC 3302 }\end{array}$ & $23.54 \pm 0.19$ & $6.95 \pm 0.06$ & 77.20 & 22.80 \\
\hline
\end{tabular}

humans is extremely low [37]. In this study, quantification of lactate produced by L. acidophilus IDCC 3302 indicated an approximate 1:4 ratio of D- to L-lactate $(6.95 \pm 0.06 \mathrm{mg} / \mathrm{ml}$ of D-lactate and $23.54 \pm 0.19 \mathrm{mg} / \mathrm{ml}$ of L-lactate) (Table 3). Compared to other Lactobacillus strains, the proportion of D-lactate produced by $L$. acidophilus IDCC 3302 is relatively low. In comparison, L. reuteri NCIMB 3053 had a 6:5 of D-/L-form ratio, $L$. delbrueckii ATCC 11842 had 12:11, L. rhamnosus GG ATCC 53103 had 3:13 [38].

\section{Acute oral toxicity in rats}

A single-dose acute oral toxicity test was performed in rats to evaluate the L. acidophilus' safety in vivo. A 14day observation revealed that a single oral dose of $7.9 \times$ $10^{9}-5.3 \times 10^{10} \mathrm{CFU} / \mathrm{g}$ of $L$. acidophilus IDCC $3302 \mathrm{did}$ not cause death or toxicity in 9 to 10 -week old rats. Also, there were no significant changes in the mice's appearance, such as skin, hair, behavior, weight, and feed intake (Table 4). No significant pathological change was found in any rat during the autopsy. Thus, there was no evidence of any toxicity in rats receiving $L$. acidophilus IDCC 3302.

In conclusion, the safety of L. acidophilus IDCC 3302 isolated from infant feces was assessed with in vitro and in vivo tests. The whole-genome analysis and MIC tests showed this strain to be safe in terms of antibiotic resistance. The analysis of the potential toxins produced by L. acidophilus IDCC 3302 showed that the strain had an extremely low probability of producing toxic compounds. Furthermore, there was no evidence of $L$. acidophilus IDCC 3302 having any toxicity in rats. Therefore, we concluded that L. acidophilus IDCC 3302 is safe as probiotics for human consumption.

\section{Acknowledgment}

This work was supported by Ildong Bioscience, Co., Ltd., and the National Research Foundation of Korea (NRF) grant funded by Korea government (Ministry of Science and ICT, MSIT) [grant number 2020R1C1C1005251].

\section{Conflict of Interest}

The authors have no financial conflicts of interest to declare.

\section{References}

1. Chandan RC. 1999. Enhancing market value of milk by adding cultures. J. Dairy Sci. 82: 2245-2256.

2. Gill H, Prasad J. 2008. Probiotics, immunomodulation, and health benefits. Adv. Exp. Med. Biol. 606: 423-454.

3. Françoise L. 2010. Occurrence and role of lactic acid bacteria in seafood products. Food Microbiol. 27: 698-709.

4. Chamba JF, Irlinger F. 2004. Secondary and adjunct cultures. pp. 191-206. In Patrick FF, Paul LHM, Timothy MC, Timothy PG (eds.), Cheese: chemistry, physics and microbiology, 3rd Ed. Elsevier Academic Press, London.

5. Alander M, Satokari R, Korpela R, Saxelin M, Vilpponen-Salmela T, Mattila-Sandholm T, et al. 1999. Persistence of colonization of human colonic mucosa by a probiotic strain, Lactobacillus rhamnosus GG, after oral consumption. Appl. Environ. Microbiol. 65: 351-354.

6. Danielsen M, Wind A. 2003. Susceptibility of Lactobacillus spp. to antimicrobial agents. Int. J. Food Microbiol. 82: 1-11.

7. Kirjavainen PV, Ouwehand AC, Isolauri E, Salminen SJ. 1998. The ability of probiotic bacteria to bind to human intestinal mucus. FEMS Microbiol. Lett. 167: 185-189.

Table 4. The body weight changes of the female rats administered with L. acidophilus IDCC 3302 at different dosages.

\begin{tabular}{ccccccc}
\hline \multirow{2}{*}{ Group } & $\begin{array}{c}\text { Dosage } \\
\left.(\mathrm{g} / \mathrm{kg} \mathrm{BW})^{1}\right)\end{array}$ & Day 0 & Day 1 & Day 3 & Day 7 & Day 14 \\
\cline { 3 - 7 } 9 week-aged & 300 & $217.1 \pm 3.2$ & $241.7 \pm 4.3$ & $246.2 \pm 10.1$ & $254.0 \pm 15.1$ & $267.4 \pm 6.9$ \\
& 2000 & $235.4 \pm 12.0$ & $260.6 \pm 13.8$ & $263.3 \pm 5.5$ & $277.6 \pm 15.9$ & $282.3 \pm 12.9$ \\
\multirow{3}{*}{10 week-aged } & 300 & $208.4 \pm 15.7$ & $223.4 \pm 19.1$ & $229.8 \pm 17.8$ & $237.7 \pm 22.6$ & $245.6 \pm 21.7$ \\
& 2000 & $215.6 \pm 10.8$ & $234.4 \pm 15.8$ & $242.2 \pm 10.5$ & $245.4 \pm 10.3$ & $259.0 \pm 13.2$ \\
\hline
\end{tabular}

${ }^{1} \mathrm{BW}$, body weight

${ }^{2}$ Values are mean \pm SD of 3 replicates 
8. Kos BVZE, Šušković J, Vuković S, Šimpraga M, Frece J, Matošić S. 2003. Adhesion and aggregation ability of probiotic strain Lactobacillus acidophilus M92. J. Appl. Microbiol. 94: 981-987.

9. Tannock GW. 1999. Probiotics: a critical review. J. Antimicrob. Chemother. 43: 849.

10. Abriouel H, Casado Muñoz MC, Lerma LL, Montoro BP, Bokelmann W, Pichner R, et al. 2015. New insights in antibiotic resistance of Lactobacillus species from fermented foods. Food Res. Int. 78: 465-481.

11. Donohue DC, Salminen S. 1996. Safety of probiotic bacteria. Asia pacific J. Clin. Nutr. 5: 25-28.

12. Saxelin M, Rautelin H, Salminen S, Mäkelä PH. 1996. Safety of commercial products with viable Lactobacillus strains. Infect. Dis. Clin. Pract. 5: 331-335.

13. Antony SJ. 2000. Lactobacillemia: an emerging cause of infection in both the immunocompromised and the immunocompetent host. J. Natl. Med. Assoc. 92: 83-86.

14. Schlegel L, Lemerle S, Geslin P. 1998. Lactobacillus species as opportunistic pathogens in immunocompromised patients. Eur. J. Clin. Microbiol. Infect. Dis. 17: 887-888.

15. Vijayalakshmi S, Adeyemi DE, Choi IY, Sultan G, Madar IH, Park MK. 2020. Comprehensive in silico analysis of lactic acid bacteria for the selection of desirable probiotics. LWT 130: 109617.

16. Chen L, Yang J, Yu J, Yao Z, Sun L, Shen Y, et al. 2005. VFDB: a reference database for bacterial virulence factors. Nucl. Acids Res. 33: D325-D328.

17. Zankari $\mathrm{E}$, Hasman $\mathrm{H}$, Cosentino $\mathrm{S}$, Vestergaard $M$, Rasmussen $\mathrm{S}$, Lund $\mathrm{O}$, et al. 2012. Identification of acquired antimicrobial resistance genes. J. Antimicrob. Chemother. 67: 2640-2644.

18. Arndt D, Grant JR, Marcu A, Sajed T, Pon A, Liang Y, et al. 2016. PHASTER: a better, faster version of the PHAST phage search tool. Nucl. Acids Res. 44: W16-W21.

19. Priyadarshani WM, Rakshit SK. 2011. Screening selected strains of probiotic lactic acid bacteria for their ability to produce biogenic amines (histamine and tyramine). Int. J. Food Sci. Technol. 46: 2062-2069.

20. EFSA Panel on Additives and Products or Substances used in Animal Feed (FEEDAP), Rychen G, Aquilina G, Azimonti G, Bampidis V, Bastos MDL, et al. 2018. Guidance on the characterisation of microorganisms used as feed additives or as production organisms. EFSA J. 16: e05206.

21. OECD. 2001. OECD Guideline for the Testing of Chemicals. No. 423: Acute Oral Toxicity - Acute Toxic Class Method, pp.14. Paris, France: Organisation for Economic Co-operation and Development.

22. Ammor MS, Flórez AB, Mayo B. 2007. Antibiotic resistance in nonenterococcal lactic acid bacteria and bifidobacteria. Food Microbiol. 24: 559-570.
23. Charteris WP, Kelly PM, Morelli L, Collins JK. 2001. Gradient diffusion antibiotic susceptibility testing of potentially probiotic lactobacilli. J. Food Prot. 64: 2007-2014.

24. Mayrhofer S, Van Hoek AHAM, Mair C, Huys G, Aarts HJ, Kneifel W, et al. 2010. Antibiotic susceptibility of members of the Lactobacillus acidophilus group using broth microdilution and molecular identification of their resistance determinants. Int. J. Food Microbiol. 144: 81-87.

25. Temmerman R, Pot B, Huys G, Swings J. 2003. Identification and antibiotic susceptibility of bacterial isolates from probiotic products. Int. J. Food Microbiol. 81: 1-10.

26. Kodner C, Kudrimoti A. 2003. Diagnosis and management of acute interstitial nephritis. Am. Fam. Physician 67: 2527-2534.

27. Kim DH, Jin YH. 2001. Intestinal bacterial $\beta$-glucuronidase activity of patients with colon cancer. Arch. Pharm. Res. 24: 564-567.

28. Choi YB, Kim KS, Rhee JS. 2002. Hydrolysis of soybean isoflavone glucosides by lactic acid bacteria. Biotechnol. Lett. 24: 2113-2116.

29. Delgado S, O' Sullivan E, Fitzgerald G, Mayo B. 2008. In vitro evaluation of the probiotic properties of human intestinal Bifidobacterium species and selection of new probiotic candidates. J. Appl. Microbiol. 104: 1119-1127.

30. Colombo M, Castilho NP, Todorov SD, Nero LA. 2018. Beneficial properties of lactic acid bacteria naturally present in dairy production. BMC Microbiol. 18: 219.

31. Spano G, Russo P, Lonvaud-Funel A, Lucas P, Alexandre H, Grandvalet $C$, et al. 2010. Biogenic amines in fermented foods. Eur. J. Clin. Nutr. 64: S95-S100.

32. Barbieri F, Montanari C, Gardini F, Tabanelli G. 2019. Biogenic amine production by lactic acid bacteria: a review. Foods 8: 17.

33. Ladero V, Calles-Enríquez M, Fernández M, Alvarez MA. 2010. Toxicological effects of dietary biogenic amines. Curr. Nutr. Food Sci. 6: 145-156.

34. Sanders ME, Akkermans LM, Haller D, Hammerman C, Heimbach JT, Hörmannsperger G. 2010. Safety assessment of probiotics for human use. Gut Microbes 1: 164-185.

35. Uribarri J, Oh MS, Carroll HJ. 1998. D-lactic acidosis: a review of clinical presentation, biochemical features, and pathophysiologic mechanism. Medicine 77: 73-82.

36. Møller PD, Diernaes L, Sehested J, Hyldgaard-Jensen J, Skadhauge $E$. 1997. Absorption and fate of $L$-and D-lactic acid in ruminants. Physiol. A Physiol. 118: 387-388.

37. Quigley EM, Pot B, Sanders ME. 2018. 'Brain Fogginess' and DLactic acidosis: probiotics are not the cause. Clin. Transl. Gastroenterol. 9: 187.

38. Sulemankhil I, Parent M, Jones ML, Feng Z, Labbé A, Prakash S. 2012. In vitro and in vivo characterization and strain safety of Lactobacillus reuteri NCIMB 30253 for probiotic applications. Can. J. Microbiol. 58: 776-787. 